\title{
Tabae Roma Dönemi Kırmızı Astarlı Seramikleri
}

\section{Oğuz KOÇYiĞiT*}

\section{Öz}

Bu çalışma Denizli ili, Kale ilçesi sınırlarında yer alan antik Tabae yerleşim yerinden ele geçmiş olan bir grup kırmızı astarlı Roma seramik kabını kapsar. Bu kırmızı astarlı kaplar, Roma döneminin tipik seramikleri olarak bilinen terra sigillataların, doğudaki merkezlerde üretilen türevlerinden oluşurlar. Daha çok Doğu Sigillataları (Eastern Sigillata) olarak adlandırılan bu kaplar, Tabae'nin Roma devri seramikleri arasında ayrı ve nitelikli bir grup oluştururlar. Bunlar arasında etütlük nitelikteki bazı kırık ya da çatlak kaplar olmakla birlikte, çoğunluğu envanterlik olarak değerlendirilen tam kaplardan meydana gelir. Bu kısa çalışma kapsamında, Tabae'de ele geçen bu Doğu Sigillataları hamur ve form özellikleri bakımından gruplara ayrılmışlar, benzerleri ile yapılan analojik değerlendirmeler sonrası tarihlenmeye çalışılmışlardır. Buna göre, kapların çoğunluğunun Bat Anadolu orijinli sigillatalar olduğu ve çeşitli merkezlerden ithal edildikleri anlaşıımıştır. Tüm bunlar, Tabae antik kentinin Hellenistik dönemden itibaren özellikle de Roma dönemi boyunca bulunduğu coğrafya içerisinde önemli bir yerleşim yeri olduğunu ve çevresindeki diğer yerleşim yerleri ile sıkı bir ticari ilişki içinde olduğunu göstermektedir.

Anahtar kelimeler: Tabae, Roma dönemi, seramik, doğu sigillataları.

\section{Red Slip Roman Pottery from Tabae}

\begin{abstract}
This study covers a group of red slip Roman pottery unearthed in the ancient Tabae, in the settlement of Kale, province of Denizli. These red slip potteries consist of different types of terra-sigillata, known as typical ceramics of the Roman period, in the eastern provinces of Roman Empire. These potteries also, more commonly called as Eastern Sigillatas, which are consist of a separate and qualified group among the Roman potteries of Tabae. Even if there are some broken or cracked samples, most of them are consisting of complete, which are evaluated as inventory samples. In the context of this brief study, these Eastern Sigillatas which are recovered in Tabae were divided into different groups in terms of clay and form, and they were also tried to be dated by analogical evaluations. According to this, it is understood that the majority of red slipped potteries from Tabae are originated from Western Anatolia and imported from many Roman centers from here. All of these indicate that the ancient city of Tabae is an important settlement in its geography during the Roman period, and has a close commercial relationship with other Roman settlements around it.
\end{abstract}

Key Words: Tabae, Roman period, pottery, eastern sigillatas.

Yrd. Doç. Dr., Çanakkale Onsekiz Mart Üniversitesi Fen-Edebiyat Fakültesi, Sanat Tarihi Bölümü.

Bu çalışma Çanakkale Onsekiz Mart Üniversitesi Bilimsel Araştırma Projeleri Koordinasyon Birimi (ÇOMU BAP) tarafindan SBA-2015-448 proje numarası ile desteklenmiştir. Bu destekten ötürü kendilerine teşekkür ederim. Ayrıca, seramik buluntuların ele geçtiği dönem Tabae Kazı Başkanlığını yürüten eski Kazı Başkanı Prof. Dr. Bozkurt Ersoy’a verdiği izinlerden, Yrd. Doç. Dr. Hasan Uçar’a da katkı ve yardımlarından dolayı teşekkürü borç bilirim. Yine kazı buluntularının korunduğu Denizli Arkeoloji Müzesi'nde çalışma imkanı sağlayan tüm müze uzmanlarına da sonsuz şükranlarımı sunarım. 


\section{GiRiş}

Denizli'ye bağlı Kale ilçesinin yaklaşık $1 \mathrm{~km}$. kadar güneybatısında yer alan ve 2006 yıIından bu yana arkeolojik kazıların yapıldığı Tabae ya da yaygın olarak Kale-i Tavas'da ele geçen kırmızı astarlı Roma seramikleri, bu çalışmanın esasını oluşturur. Osmanlı ve Beylikler dönemi ile birlikte, Bizans ve Roma tarihinin de aydınlatıldığı bu yerleşim yerinde, özellikle 2009, 2011 ve 2012 yıllarında yapılan kazılar sırasında heykeller, sikkeler ve cam eserlerle birlikte, etütlük ve envanterlik nitelikte çok sayıda Roma dönemi seramik kabı açığa çıkarılmıştır. Bunlar arasında terra sigillata olarak adlandırılan dönemin kırmızı astarlı ince sofra kapları başta olmak üzere, çeşitli depolama ve taşımaya yönelik çok sayıdaki günlük kullanım kabı sayılabilir ${ }^{1}$.

Tüm Akdeniz coğrafyasına yayılmış olan ve Roma döneminin gerek zevk gerekse sanatsal üslubunu en iyi biçimde yansıtan, bu dönemin tipik seramikleri olarak bilinen terra sigillatalarının, doğudaki merkezlerde üretilen varyasyonları yani, Doğu Sigillataları (Eastern Sigillata) olarak bilinen kırmızı astarlı kaplar ise, Tabae'nin Roma devri seramikleri arasında ayrı ve nitelikli bir grup oluştururlar. Bunlar arasında etütlük nitelikteki bazı kırık ya da çatlak kaplar olmakla birlikte, çoğunluğu envanterlik olarak değerlendirilen tam kaplardan oluşurlar. Bu eserler, çalışma kapsamında hamur ve form özellikleri bakımından gruplara ayrılmışlar, benzerleri ile yapılan analojik değerlendirmeler sonrası tarihlenmeye çalışıımışlardır.

\section{TABAE ANTIK KENTI VE KISA TARIHI}

Antik dönem Lydia ve Karia kültür bölgelerinin sınırında yer alan Tabae, Aphrodisias (Geyre)'ın hemen güneydoğusunda, Moballa (Muğla) yolu üzerinde bulunur. Apollonia (Medet), Heracleia (Vakıf Köyü) ve Sebastopolis (Kızılca) gibi kentlere oldukça yakın olup, Salbakos dağının eteklerinde yer alır². Bir çok antik kaynakta Lidya'nın güneydoğu sınır bölgesi olarak aktarılan Karia bölgesinin bu kısmı, aynı zamanda Frigya ve Pisidia bölgelerinin kültür sınırları içerisinde de yer alır. Prehistorik dönemlerden itibaren önemli bir yerleşim bölgesi üzerinde bulunan Tabae'nın tam olarak ne zaman kurulduğu bilinmemekle birlikte, kentin Tunç Çăğ'ndan bu yana devam eden bir iskana sahip olduğu kabul edilebilir. Kentte yapılan yüzey araştırmaları ve kazı çalışmalarında Tunç Çağı'na ait önemli bulgular ele geçmesi bunun göstergesidir ${ }^{3}$. Kentte özellikle de İç Kale'de yapılan kazılar sırasında ele geçen seramiklerden en erken tarihli olanların, M.Ö. 2000-1200 yıllarına tarihlenen, Beycesultan ile paralel Geç Tunç Çağı seramikleri olduğu görülür ${ }^{4}$. Yine Geç Geometrik ve Arkaik dönemlere ait erken dönem boyalı Yunan seramikleri ile birlikte, Yunan anakarasından ithal edilmiş olan Korinth seramiklerinin de burada yoğun

1 Bahsi geçen eserler, seramik kapların ilk ortaya çıkarıldı̆̆ı dönemde kazı heyet üyesi olan Sevinç Gök ve Hasan Uçar tarafindan genel olarak ele alınmışlar, kentteki Beylikler ve Osmanlı dönemi seramikleri ile birlikte, kısaca tanıtımışlardır. Bkz: S. Gök - H. Uçar, "Kale-i Tavas (Tabae) Kazısı Seramik Buluntuları (2007-2011)", Kaledavaz Sempozyum Bildirileri (2-3 Nisan 2012), (ed: T. Tok - Ö.K. Aydemir), Denizli. 2013, s: 402-412.

2 R. J. A. Talbert, (ed.), Barrington Atlas of the Greek and Roman World, Princeton. 2000, harita no: 54.

3 M. Beyazıt, "Kale-i Tavas (Tabae) Kazıları", Geçmişten Günümüze Denizli, Denizli'nin Derin Geçmişi, Kazı ve Araştırmalar II, Denizli. 2016, s: 64.

4 R. G. Gürtekin-Demir - Y. Polat, "Between Lydia and Caria: Iroın Age pottery From Kale-i Tavas, Ancient Tabae", Karamos, Ceramics: A Cultural Approach. Proceedings of the First International Conference at Ege University (9-13 May 2011), (ed: R.G. Gültekin-Demir et al), Ankara. 2015. s: 116. 


\section{Uluslararası Sosyal Bilimler Dergisi}

olarak ele geçtiğini söylemeliyiz ${ }^{5}$. M.Ö. 7. ve 6. yüzyıllara tarihlenen dalga bezemeli Karia yerel üretimi seramiklerde erken döneme tarihlenen örnekler arasındadırlar ${ }^{6}$.

Antik Çağ'da ve özellikle Roma dönemi ile birlikte Tabae'nın gelişmiş bir yerleşim yeri ve önemli bir kent olduğu görülür. Zira Tabae ismi Roma dönemi ile birlikte artk yazılı kaynaklarda zikredilmekte ${ }^{7}$, kent hakkında çeşitli bilgiler elde edilebilmektedir (Res. 1). Ayrıca M.Ö. 2. yüzyıl ortalarından M.S. 3. yüzyıl ortalarına kadar şehir sikkelerinde kentin adı görülmektedir ${ }^{8}$. Kent, daha sonra Bizans döneminde psikoposluk listelerine girmiş̧ ${ }^{9}$ ancak eski önemini ve gücünü yitirmiştir. M.S. 12. yüzyıl başlarında Selçukluların bölgeye hakim olması ile birlikte artk Türk hakimiyetine geçmiştir. Bundan sonra bir Türk yerleşimine dönüşen Tabae, artk Kale-i Tavas ismini alarak Menteşe Beyliği'nin önemli kentlerinden biri olmuştur.

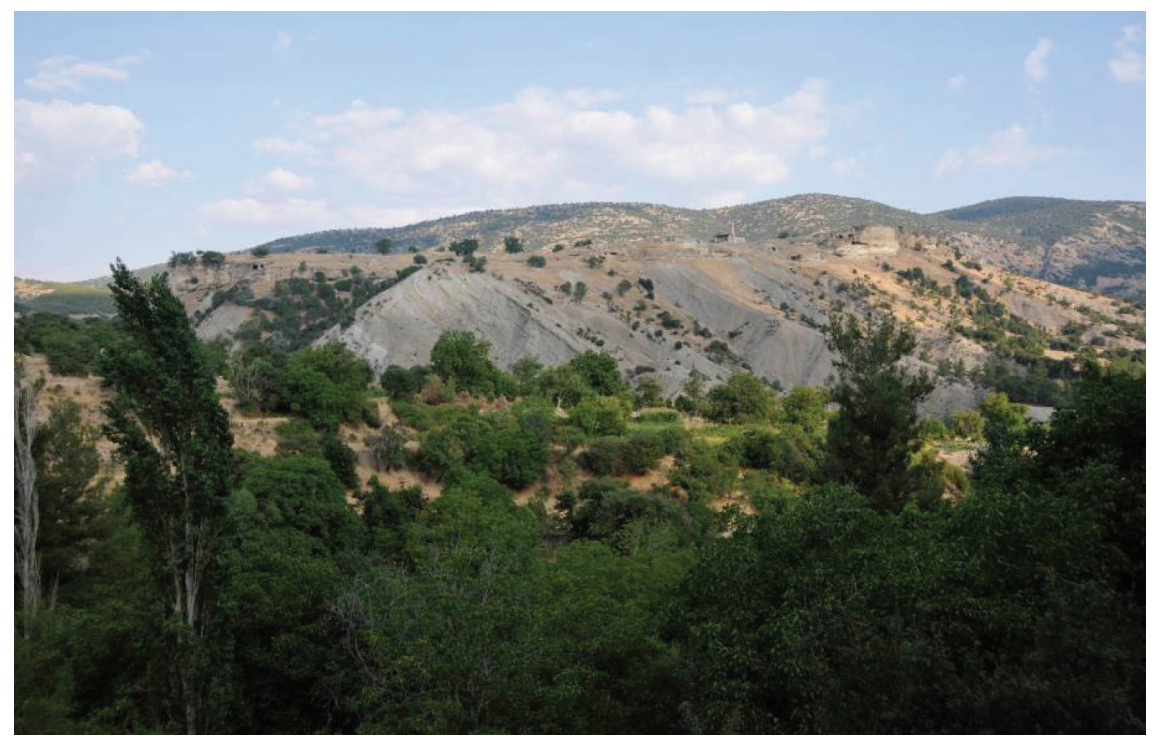

Resim 1. Kale ilçesinin hemen güneyinde, doğal kayalık bir alan üzerine oturan Tabae antik kenti.

\section{TABAE'DA ROMA DÖNEMI SERAMIKLERININ BULUNTU YERLERi}

Tabae'da 2006 yılından itibaren Prof. Dr. Bozkurt Ersoy başkanlığında başlanan kazı çalışmaları sırasında tespit edilen ve aynı yı içinde kazısına başlanan I no'lu sarnıç ile birlikte, ilerleyen zamanlarda kazılan III no'lu sarnıç, şimdilik Roma dönemi seramiklerinin ele geçtiği başlıca buluntu yerleridir.

Kuzeydoğu-güneybatı yönünde uzanan I no'lu sarnıç, beşik tonozlu iki birimden oluşmaktadır. Bu birimler, kare kesitli dört destek üzerine oturan yuvarlak kemerlerle birbi-

Gürtekin - Demir ve Polat 2015, s: 116.

Gök - Uçar 2012, s: 402; Gürtekin - Demir ve Polat 2015, s: 116.

Strabon 12.7 .2 ve 12.8 .13

C. Ünal, "Coin Findings and Two German Tokens from Excavation of Tabae/Kale, Denizli", Sanat Tarihi Dergisi XVIII/2, 2009, s: 138.

9 W.M. Ramsay, The Historical Geography of Asia Minor, London, 1890, s: 49, 421. 
rinden ayrılmıştır. Burada 2012 yııına kadar devam eden kazı çalışmaları sonunda, sarnıcın içerisindeki dolgu toprağı tamamen kazılmış ve yapı ortaya çıkarılmıştır. Böylece sarnıcın ortasında yer alan ve yapıyı ikiye ayıran 5 kemer gözü tamamen ortaya çıkartılmış ve yapının planı çıkarılabilmiştir ${ }^{10}$ (Res. 2).

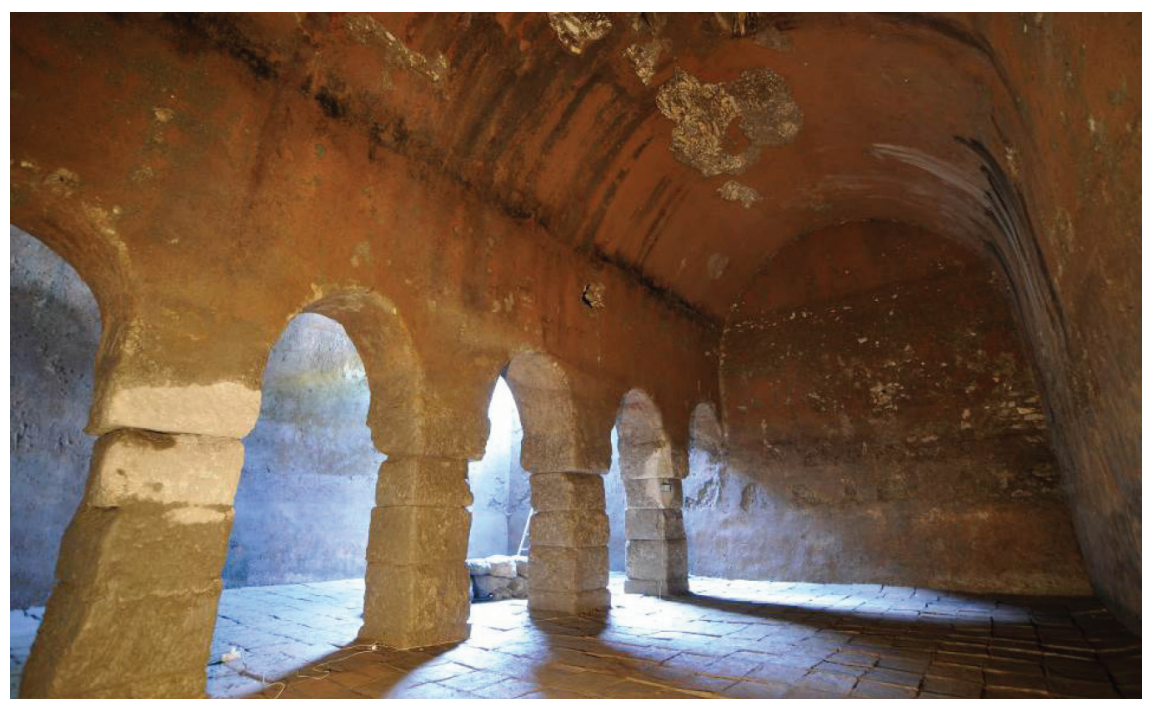

Resim 2. I no'lu sarnıcın kazı sonrası görünümü (Ersoy 2012).

Sarnıç, dört destek üzerine oturan yuvarlak kemerlerle iki bölüme ayrılmaktadır.

Sarnıç içerisinde, boşaltılan dolgu topraktan bol miktarda seramik, sikke, metal ve mermer buluntular ele geçirilmiştir ${ }^{11}$. Özellikle, birçoğu sağlam ve tamamlanabilecek durumda Roma dönemine ait çeşitli sofra kapları ve su testileri ile birlikte, çeşitli mermer ve bronz heykeller, kandiller, figürinler ile yüzeyleri tahrip olmuş çok sayıda sikke, sarnıcın yoğun olarak kullanıldığı Roma dönemine ait önemli buluntulardır ${ }^{12}$. I no'lu sarnıçtan ele geçen seramik buluntuların daha çok testi ve benzeri nitelikteki sofra kapları ile birlikte, kandillerden oluştuğunu söyleyebiliriz.

Tabae'da, kale girişi yanındaki I no'lu çeşmenin yakınındaki III no'lu sarnıcın da tıpkı diğer sarnıçta olduğu gibi, günümüze kadar geçen süreç içerisinde akan moloz ve toprak nedeniyle dolduğu görülmüştür (Res.3). Yapılan çalışmalar sırasında ele geçen bol sayıdaki Roma seramik buluntusu, bu sarnıcın da Roma döneminde yoğun olarak kullanıldığını gösterir $^{13}$. Öyle ki, ağız kısmına kadar dolu olan sarnıcın, en üst seviyesinde ortaya çıkartılan buluntuların daha çok Roma imparatorluk dönemine ait buluntular olması, sarnıcın

10 B. Ersoy, "Kale-i Tavas (Tabae) Kazıları”, Ege Üniversitesi Arkeoloji Kazıları (ed: A. Çilingiroğlu vd.), İzmir. 2012, s: 421-424.

11 B. Ersoy, “Kale-i Tavas (Tabae) 2007 Yılı Kazısı", Kazı Sonucları Toplantısı 30/3, Ankara. 2009, res: 10-11; B. Ersoy, "Kale-i Tavas (Tabae) 2008 Yılı Kazı Çalışmaları", Kazı Sonucları Toplantısı 31/3, Ankara. 2010, res: 9-10; Ersoy 2012, res: 6-7.

12 Ersoy 2012, s: 421-424.

13 Ersoy 2012, s: 429. 


\section{Uluslararası Sosyal Bilimler Dergisi}

bu dönemde dolmuş olabileceğini akıllara getirmektedir ${ }^{14}$.

Burada belirtilmesi gereken en önemli husus, III no'lu sarnıç içerisinde ele geçen seramik buluntuların, I no'lu sarnıçta ele geçenlerden farklı olarak, daha çok kırmızı astarlı Roma tabak ve kaselerin ağılıkta olduğu ince sofra kaplarından oluştuğudur. Zira, bu çalışmanın konusunu oluşturan kırmızı astarlı kaplarda, genel olarak bu sarnıçtan ele geçen buluntulardan oluşmaktadır.

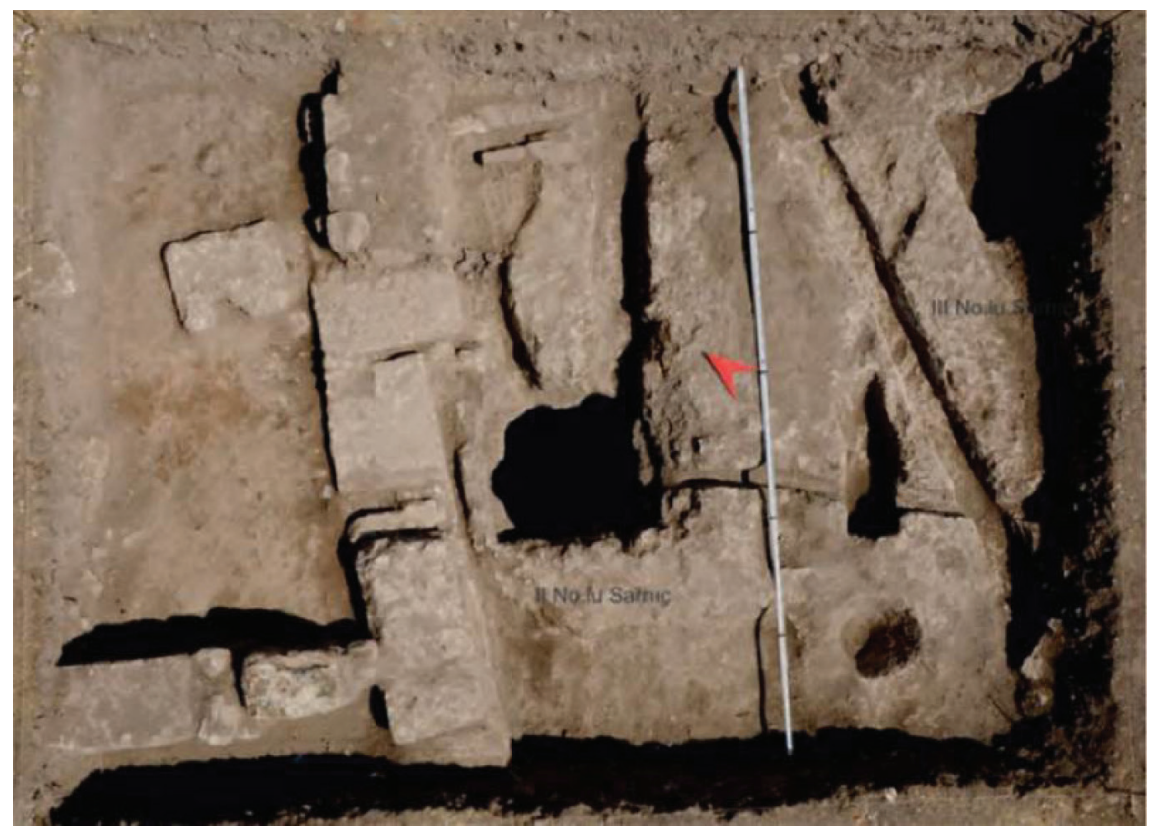

Resim. 3. Tabae'da II ve III no'lu sarnıçların giriş kısımları (Ersoy 2012).

\section{HAMUR ÖZELLIKLERI VE FORM GRUPLARI}

Tabae'da, ağırlıklı olarak III no'lu sarnıç kazılarında ortaya çıkarılan ve bu çalışma kapsamında ele alınan Roma dönemi kırmızı astarlı kase ve tabaklarının daha çok ithal ya da ithal taklidi ürünler olduğu söylenebilir. İthal kapların özellikle Batı Anadolu'da Pergamon başta olmak üzere, Trailleis, Çandarlı ve Tarsus'da sıklıkla üretimi yapılan Doğu Sigillataları'nın (Eastern Sigillata) çeşitli tiplerinden oluştuğu, ithal taklidi ürünlerinde yine bu Doğu Sigillataları́nın belli formlarının yerelde üretilen örnekleri olduğunu söyleyebiliriz ${ }^{15}$. Batı Sigillataları (Western Sigillata) olarak adlandırılan İtalya ve Gaul üretimi terra sigillataların ise şimdilik Tabae'de bilinmeyen kap türleri olduğunu söylemeliyiz.

Doğu Sigillataları olarak adlandırılan kase ve tabak benzeri kaplar, Tabae'da sarnıç buluntusu olarak değerlendirilen toplam 226 adet Roma dönemi seramik buluntusu içerisin-

14 Ersoy 2012, s: 429.

15 Doğu Sigillatalarının üretim yeri problemi ile ilgili olarak bkz: Zoroğlu, L., "Dogu Sigillataların İmalat Yerleri ve Dağılım Sorunu", Varia Anatolica XV; Les Ceramiques En Anatolie Aux Epoques Hellenistique et Romane, (ed. C. Abadie-Reynal), İstanbul. 2003, s: 121-123. 
de, 26 adetlik sayıları ile \% 12'lik küçük bir orana sahiptir. Ancak buna rağmen, günlük kullanım ve depolama amacına yönelik büyük kapların \% 88 'lik büyük bir orana sahip oldukları görülür. Muhakkak ki bu dağılımdaki orantısızlığın en büyük sebebi Tabae seramiklerinin tamamının şimdilik bu sarnıçlardan ele geçmiş olmasıdır. Kent içerisinde ya da kentin diğer yapılarında yapılacak olan kazı ve araştırmalar ile kırmızı astarı ınce sofra kaplarının artı̧ göstereceği söylenebilir. Ancak, bu haliyle bile Tabae'daki kırmızı astarlı Roma seramiklerinin ya da Doğu Sigillataları'nın oldukça zengin bir form çeşitliliği gösterdiği söylenebilir.

Az önce de belirttiğimiz gibi, Doğu Sigillataları olarak tanımlayabileceğimiz kırmızı astarlı ince sofra kapları Tabae Roma dönemi seramikleri arasında sayısal olarak küçük bir grubu oluştururlar. Ancak, Roma dönemi seramikleri içerisinde en iyi tarihlenebilen kaplar da yine bu gruba dahil olanlardır.

\subsection{Hellenistik karakterli kaseler}

Tabae Roma kapları arasında, kase formundaki seramiklerin en erken örnekleri Hellenistik karakterde olan (kat. no. 1-5) kaplardan oluşur. Bu kaplarda kullanılan hamur grubu, daha çok koyu kahverengi (7.5 YR 4/6 - 5/6 - 5/8) olup, çok az mika katkılıdır. Oldukça sert bir dokuya sahip bu hamur, sıkı ve kaliteli pişirimlidir.

Bu hamurun kullanıldığı kaplarda astar, çoğunlukla kırmızı renk (2.5 YR 5/8) parlak ve perdahlı iken (kat. No. 1-4), zaman zaman da koyu kahverengi (7.5 YR 3/4)' dir. Tabae kapları arasında özellikle bir örnekte astarın bu şekilde olduğu açıkça belli olur (kat. no. 5). Ayrıca bu kapta aşınmadan dolayı astarın içte ve dışta yer yer döküldüğü de anlaşılır (Res. 4).

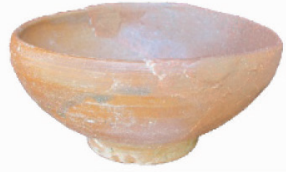

1

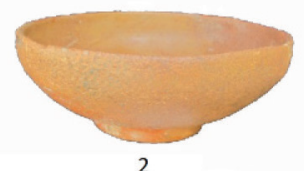

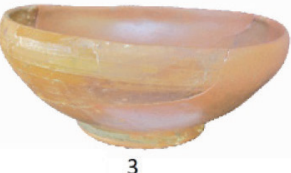

3

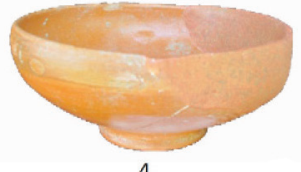

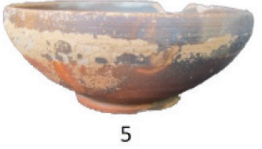

5

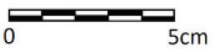

Resim. 4. Tabae'da ele geçen Hellenistik dönem kaseleri.

Tamamı halka kaideli olan bu grupta, gövdenin küresel olması yanında, geniş ağzın içe çekik biçimde form almış olması en belirleyici unsurdur. Bu kaselerin form olarak benzerleri Rothroff tarafindan Atina Agorası'nda M.Ö. 3. yüzyıldan başlayarak M.Ö. 1. yüzyı- 
la kadar uzanan geniş bir zaman aralığına tarihlendirilirler ${ }^{16}$. Tarsus Gözlükule'de ise yine bu formun oldukça yakın benzeri olan Hellenistik kaselerin M.Ö. 3. yüzyıl sonundan 2. yüzyıl başlarına kadar tarihlendirildiklerini görebiliriz ${ }^{17}$. Paphos'da ise Hayes tarafindan yapılan çalışmalar sonrası yine bu tür içe çekik ağızlı Helenistik kaseler çeşitli gruplara ayrılmışlar ve bunlar en erken 3. yüzyıla tarihlenmişlerdir ${ }^{18}$.

\subsection{Doğu Sigillataları A}

İlk olarak MÖ. 2. yüzyıl ortalarından itibaren başta Kuzey Suriye olmak üzere, Anadolu'da Pergamon, Tarsus ve Antakya gibi merkezlerde üretilen Doğu Sigillataları A grubu seramikleri Tabae'da çok az örnek ile temsil edilir. Bu hamur grubunda, hamur açık sarımsı ya da gri sarımsı renkte olup, ince elenmiş az mikalı ya da mikasızdır ve oldukça sert pişirimli olması ile de tipiktir. Bu hamura sahip kapların astarı da yine oldukça kalitelidir. Astar rengi zaman zaman mat kırmızı ya da kırmızımsı kahverengi olmakla birlikte genellikle kalitelidir ${ }^{19}$.

Tabae kırmızı astarlı seramikleri arasında bu gruba dahil edilebilecek iki örnek bulunur. Bunlar dudak kısımları dışa sarkık olan sığ biçimdeki tabaklardır (kat. no. 6 ve 7). Hamurları sarımsı kırmızı renkte olup (5. YR 5/6 - 5/8), mikasız ve oldukça sert pişirimlidir. Birinin kırmıı renk (2.5 YR 4/6) parlak ve perdahlı bir astara, diğerinin ise yine kırmızı renk (10 R 4/8) parlak ve perdahlı, ancak yer yer aşınmış bir astara sahip olduğu görülür. Pergamon üretimi olduğunu söyleyebileceğimiz bu iki tabak, form ve biçim olarak Hayes'in tipolojisindeki form 5 ile yakın özellikler gösterirler. Atina Agorası'ndaki bu forma ait tabakların, Hayes tarafindan erken 2. yüzyıla tarihlendiklerini söyleyebiliriz ${ }^{20}$.

\subsection{Doğu Sigillataları B}

Üretim yeri oldukça uzun bir süre bilim adamlarını meşgul eden bu gruptaki seramiklerin, çoğunlukla Trailles'de üretildikleri kabul edilir ${ }^{21}$. Tabae Roma kapları arasında yer alan ve kırmızı astarlı ince sofra kapları içerisinde en yoğun grubu oluşturan bu türe ait kapların hamuru, sarımsı kırmızıdan, kırmııının çeşitli tonları arasında değişen farklı tonlarda olup, bol mika katkılı ve kısmen sert dokuludurlar. Doğu Sigillataları B grubu olarak adlandırılan bu seramik türü DSB I ve DSB II olarak kendi içinde iki ayrı gruba ayrılır²2.

16 S. I. Rotroff, Hellenistic Pottery Athenian and Imported Wheelmade Table Ware and Related Material, Princeton. 1997, fig. 62, 986-989, fig. 63, 993-1004.

17 F. F. Jones, The Pottery, Excavations at Gözlü Kule, Tarsus, Vol. I. (ed:H. Goldman), London. 1950, lev: 180, no: 80

18 J. W. Hayes, Paphos III. The Hellenistic and Roman Pottery, Nicosia, 1991, lev: 14 no: 5 ve 8.

19 H. Goldman, Excavations at Gözlükule. Tarsus Volume I, Princeton. 1950, s: 172; D. Erol, "Symrna Devlet Agora Buluntusu Terra Sigillatalari", Çanak, Late Antique and Medieval Pottery and Tiles in Mediterranean Archaeological Contexts, Proceedings of the First International Symposium Late Antique and Medieval Pottery and Tiles in Archaeological Contexts, (Çanakkale 1-3 June 2005), (eds. Beate Böhlendorf-Arslan - Ali Osman Uysal - Johanna Witte-Orr), İstanbul. 2007, s: 75.

20 J. W. Hayes, Roman Pottery. Fine-ware Imports. The Athenian agora: results of excavations conducted by the American School of Classical Studies at Athens 32, Princeton, 2008, fig. 3, 63.

21 J. W. Hayes, "Roman Pottery from the South Stoa at Corinth", Hesperia 42, 1973, s: 452; J. W. Hayes, Late Roman Pottery, Rome. 1972, s: 9 vd.

22 J. W. Hayes, "Sigillate Orientali", Enciclopedia dell'Arte Classica e Orientale. Atlante delle Forme Ceramiche II: Ceramica Fine Romana nel Bacino Mediterraneo (Tardo Ellenismo e Primo Imperio), Roma. 1985, s: 49-70; C. Meyer-Schlichtmann, Die Pergamenische Sigillata aus Der Statgrabung von Bergama, PF6, Berlin-New York. 1988, s: 11. 
Doğu Sigillataları B I grubuna ait kapların hamuru genellikle iyi elenmiş, bol mikalı ve iyi pişirimlidir. Renk, pembemsi kahverengi ile kırmızının çeşitli tonlarında olabilmektedir. Astar ise parlak kırmızı olup sabunumsu bir kayganlıktadır ${ }^{23}$. Tabae'daki Roma kapları arasında toplam beş tabak/kase ile temsil edilen DSB I grubu kaplarının (kat. no. 9-1011-12-13), hamurları sarımsı kırmızı ile kırmızının çeşitli tonları arasında değişir (5 YR 4/6, 5/8, 6/6 - 2,5 YR 3/6, 6/6, 5/8). Kapların astarları parlak kırmızı olup (2.5 YR 4/8, $5 / 8,6 / 6,6 / 8$ ), ince cidarlı ve gayet düzgün yapılmışlardır (Res. 5).

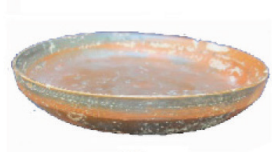

10

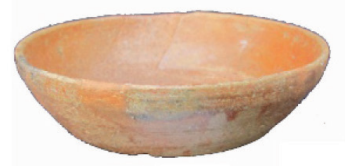

13
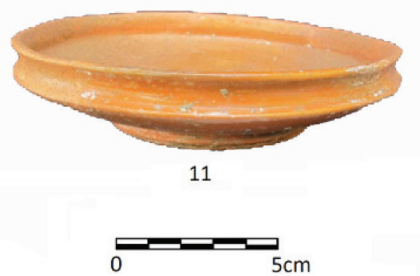

Resim 5. Tabae'da ele geçen Doğu Sigillataları BI grubuna ait tabaklar.

Bu gruba dahil edilen tabaklardan ikisi halka kaideli olup (kat. no. 11-12), diğer üçü düz kaidelidir (kat. no. 9-10, 13). Bunlardan 11 katalog numaralı olan tabak Hayes'in Atina Agorası'nda ele aldığı 191 numaralı kap ile form ve biçim açısından paralellik gösterir ve M.S. 1. yüzyılın ilk yarısına tarihlenir ${ }^{24}$. 12 katalog numaralı eser ise, yine Hayes'in çalışmasında yer alan 222 katalog numaralı eser ile form ve biçim açısından oldukça benzerdir. Bu form Hayes tarafindan M.S. 1. yüzyıla ve 2. yüzyıl başlarına tarihlenir ${ }^{25}$. 9, 10 ve 13 katalog numaralı tabaklar ise aynı yayındaki 219 numaralı eser ile çok yakındır. Bu eser de yine Hayes tarafindan 1. yüzyılın ilk yarısına tarihlenir ${ }^{26}$. Bu gruba ait çok sayıdaki benzer örnek Ephesos Agorası'nda ${ }^{27}$, Smyrna Agorası'nda ${ }^{28}$, Tralleis'de $^{29}$, Tarsus'da $^{30}$ ve Anemourium'da ${ }^{31}$ ele geçmiştir.

23 Hayes 1973, s: 452; Erol 2007, s: 77.

24 Hayes 2008, fig.7, 191

25 Hayes 2008, fig.8, 222

26 Hayes 2008, fig.8, 219

27 V. Gassner, Das Südtor der Tetragonos Agora. Keramik und Kleinfunde, Forschungen in Ephesos 13, Wien. 1997, s: 131 Taf. 42 no. 500-503; R. Meriç, Spathellenistisch-Römische Keramik und Kleifunde aus Einem Schachtbrunnen amStaatsmarkt in Ephesos, FiE IX/3, Wien. 2003, s: 51, Taf. 22;

28 D. Erol, Tralleis Kenti Kazılarında Ele Geçen isim Baskılı Terra Sigillatalar, Adnan Menderes Üniversitesi Sosyal Bilimler Enstitüsü (Yayımlanmamış Yüksek Lisans Tezi), Aydın. 2004, s: 77-80.

29 Erol 2004, s: 32-33.

30 Jones 1950, s: 186-187, no.554-55, 561, 562, Fig.196

31 C. Williams, Anemurium. The Roman and Early Byzantine Pottery, Wetteren. 1989, s: 18-20, no.104110, Fig.7 
Doğu Sigillataları B II grubuna ait kaseler ise (kat.no. 14-25), Tabae'daki ince sofra kapları içerisinde en yoğun grubu oluştururlar. DSB II olarak adlandırılan bu kap grubunda hamurun genellikle daha kaba bir yapıya sahip olduğu, yumuşak ve çok daha fazla mika katkılı olduğu bilinir. Çok iyi pişirilmemiş olan bu grup kaplarının hamurları çoğunlukla yumuşak ve kat kat görünümlüdürler.

Tabae'daki DSB II grubuna dahil edilebilecek kase ve tabaklarda kalın cidarlı ve çoğu kez kötü pişirildikleri için bu şekilde, yumuşak ve gevrek görünümlüdürler (kat. no. 14-1516-17-18-19-20-21-22-23-24). Açık kırmızı (2.5 YR 5/6, 6/6) ya da sarımsı kırmızı renkte olan (5 YR 5/6, 5/8) hamur bu grubun tipik bir özelliği olarak oldukça fazla mika katkılıdır ve yine bu katkı maddelerinden dolayı da katmansı bir görünümdedir. Astar ise yine kırmızının çeşitli tonlarında olup (2.5 YR 5/6, 6/8, 7/8 - 10 R 4/8, 5/6, 6/8), genelde parlaktır ve kalınca uygulanmıştı. Ayrıca çoğunlukla da kaplarda küçük benekler şeklinde bazı dökülmeler söz konusudur (Res. 6).

Tabae'daki sadece bir örnek bunlar arasında istisna sayılabilir ve oldukça parlak sabunumsu pürüzsüz astarı, katkısız sert dokulu hamuru ile (kat. no. 25) bu gruptaki diğer örneklerden farklılaşır. Hayes form 5B grubuna dahil edilebilecek olan bu kase M.S. 2. yüzyıla tarihlenir ${ }^{32}$. Ancak, bu gruptaki kapların büyük bir çoğunluğu Hayes'in Atina Agorası'ndaki tipolojisine göre form 8 grubuna dahil edilebilecek örneklerden oluşur (kat. No. 14-22). Bu gruba dahil edilen örnekler Agora'da M.S. 1. yüzyıl ortalarından 2. yüzyıla kadar tarihlenirler ${ }^{33}$.

Yine Hayes'in tipolojisine göre form 4 grubuna dahil edilebilecek olan (kat no. 23-24) tabaklarda dikkate değer eserler arasındadırlar. Bu örnekler ise yine Hayes tarafindan Agorada M.S. 1. yüzyıl sonu ve 2. yüzyıl başlarına tarihlenirler ${ }^{34}$. DSB II grubu sigillataları, Anadolu'da başta Trailles ${ }^{35}$ olmak üzere, Ephesos'da ${ }^{36}$ ve Smyrna'da ${ }^{37}$ çok sayıda ele geçmişlerdir.

32 Hayes 2008, fig. 12. 336.

33 Hayes 2008, fig. 13, 400-414.

34 Hayes 2008, fig. 12, 346

35 Erol 2004, s: 76, çiz. 447. 453. 482-83.

36 Gassner 1997, 127. 133. Taf. 43 Nr. 508. 510.

37 Erol 2007, s: 80-81, çiz. 37-43 


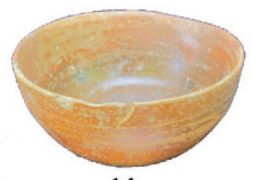

14

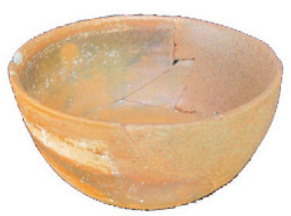

16

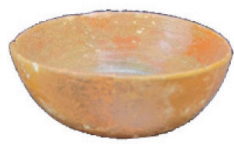

15

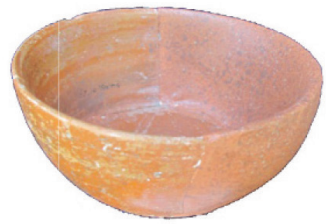

17

Resim 6. Tabae'da ele geçen Doğu Sigillataları Bll grubuna ait tabaklar.

\subsection{Doğu Sigillataları C}

Batı Anadolu'da, Çandarlı üretimi sigillataları olarak bilinen ve Doğu Sigillataları C grubu olarak adlandırılan kapların hamur olarak iyi elenmemiş, kaba katkılı oldukları bilinir. Bu kaplar, sıkı, ince ya da orta ince taneli, altın ve gümüş mika içerirler. Kırmızının tonlarında ve ağırlıklı olarak kırmızımsı kahverenginde olup, astarının çok kaliteli olduğu söylene$\mathrm{mez}^{38}$. Tıpkı Doğu Sigillataları A grubu gibi, Tabae kapları arasında sadece bir tabakla (kat. no. 8) temsil edilen C grubuna ait kabın hamuru kırmızı renk (2.5 YR 5/6), az mika ve ince kum katkılı olup, sert dokuludur. Astarı ise, kırmızı renk (2.5 YR 4/6) parlak ve perdahlıdır.

Tabae'da ele geçmiş olan bu kap, form ve biçim olarak Çandarlı üretimi kırmızı astarlı kapların erken örnekleri arasında sayılabilecek bir form özelliğine sahiptir. Zira Hayes tarafindan Atina Agora'sındaki benzerleri M.S. 1. yüzyıl ortalarına tarihlenmiştir ${ }^{39}$.

\subsection{Maşrapa ve kadehler}

Maşrapa ve kadehlerden oluşan küçük bir grup ince sofra kabı da burada değerlendirebileceğimiz bir başka eser grubudur. Daha çok bazı günlük kullanım kaplarında karşımıza çıkan kum ve taşçık katkılı, kırmızı renk bir hamura sahip bu kaplar, kısmen yerel üretim imitasyon kaplar gibi durmaktadırlar (Res. 7). Bu hamur türü, başta kırmızımsı sarı (5 YR 5/6) olmak üzere, koyu kahverengi (7.5 YR 5/8)'nin çeşitli tonlarında olup, az mika fakat yoğun miktarda kum, taşçık hatta kuartz içermekle birlikte, orta sert dokuludur.

38 Hayes 1972, s: 316-317; Erol 2007, s: 81.

39 Hayes 2008, fig. 24, no: 775. Ayrıca bkz: H. S. Robinson, Pottery of the Roman Period, Athenian Agora V, Princeton. 1959, pl. 62, G28/G70 (Samian A olarak geçer, Loeschcke tip 15). 


\section{Uluslararası Sosyal Bilimler Dergisi}

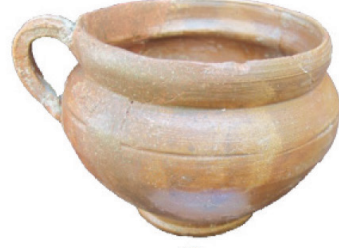

26

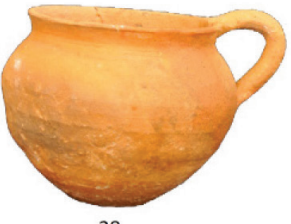

28

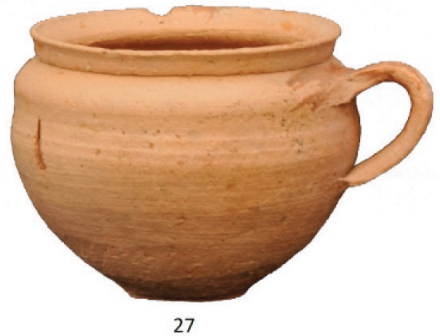

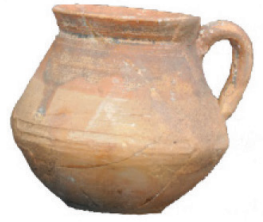

29

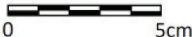

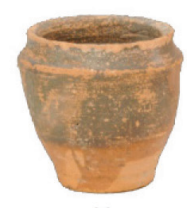

30

Resim 7. Tabae'da ele geçen kum ve taş̧ık katkılı, kırmızı renk hamurlu maşrapalar ve kadeh.

Astar olarak, kapların büyük bir çoğunluğunda (kat no. 26, 27, 28,) hamurun perdahlanmasıyla elde edilmiş, kendi rengine yakın parlak bir astar kullanılmış iken, bazılarında (kat. No. 29, 30) kalitesiz olduğu anlaşılan kahverengimsi bir astar (7.5 YR 3/2, 4/6, 6/3, 6/4) kullanıldığı anlaşılmaktadır.

Tamamı sağlam olarak günümüze ulaşabilmiş maşrapa örnekleri hafif dışa çekik, yüksek ağız kenarlı olup kaideye doğru daralan şişkin ve alçak bir gövdeye sahiptirler. Bu maşrapalardan 28 ve 29 katalog numaralı olanların, benzerleri Robinson tarafindan M.S. 1. yüzyııın sonları ve 2. yüzyılın başlarına tarihlenirler ${ }^{40} .26$ ve 27 numaralı maşrapaların ise Atina Agorası'ndaki benzerleri ${ }^{41}$ Rothroff ve Hayes tarafindan M.S. 2. yüzylla tarihlendirilirler. Ayrıca benzer kaplar Paphos'da da aynı döneme verilirler. 30 katalog numaralı kulpsuz kadeh ise yine Robinson tarafindan Athena Agorası'nda ele geçen benzerlerinin M.Ö. 1. yüzyıla tarihlenmesi nedeniyle, bu döneme atfedilebilir ${ }^{42}$.

Burada belirtilmesi gereken bir diğer husus da, bu gruba dahil edilen maşrapa ve kadehlerden sadece biri hariç (kat. No. 26), diğerlerinin (kat. No. 27-30) I no'lu sarnıçtan ele geçtikleridir.

4028 katalog numaralı eser için bkz: Robinson 1959, pl. 7, G182; 29 katalog numaralı eser için ise pl. 7, G119. Ayrıca bkz: Hayes 2008, fig. 50-51 ve pl: 76, no: 1596

41 Robinson 1959, G182 / J11, J. W. Hayes, Paphos III. The Hellenistic and Roman Pottery, Nicosia. 1991, fig: XXII, 17; Hayes 2008, fig: 51, 1604-1606.

42 Robinson 1959, F.20. 


\section{KATALOG}

\section{Hellenistik Dönem Kaseleri}

1: Kase

Env. No: 6540

Çiz. No: $1 / 1$

Tanım: Geniş ağızlı ve küresel gövdelidir. Kaidesi halka biçimli olup yüksektir. Kırmızı renk (2.5 YR 5/8) parlak ve perdahlı astar. Koyu kahverengi (7.5. YR 5/6), az mika ve ince kum katkılı, sert dokulu hamur. Yarısı kırık olup sonradan tümlenmiştir.

2: Kase

\section{Env. No: 6541 \\ Çiz. No: $1 / 2$}

Tanım: Kısmen bütün olup, geniş ağızlı ve küresel gövdelidir. Kaidesi halka biçimli olup yüksektir. Kırmızı renk (2.5 YR 5/8) parlak ve perdahlı astar. Koyu kahverengi (7.5. YR 4/6), az mika ve ince kum katkılı, sert dokulu hamur.

3: Kase
Env. No: 6542
Çiz. No: $1 / 3$

Tanım: Geniş ağızlı ve küresel gövdelidir. Kaidesi halka biçimli olup yüksektir. Kırmızı renk (2.5 YR 5/8) parlak ve perdahlı astar. Koyu kahverengi (7.5. YR 5/8), az mika ve ince kum katkılı, sert dokulu hamur. Ağızda bazı kısımları kırık olan kap sonradan tümlenmiştir.

4: Kase
Env. No: 6543
Çiz. No: $1 / 4$

Tanım: Geniş ağızlı ve küresel gövdelidir. Kaidesi halka biçimli olup yüksektir. Kırmızı renk (2.5 YR 5/8) parlak ve perdahlı astar. Koyu kahverengi (7.5. YR 5/8), az mika ve ince kum katkılı, sert dokulu hamur. Ağızda bazı kısımları kırık olan kap sonradan tümlenmiştir.

\section{5: Kase}

Env. No: 7041

Çiz. No: $1 / 5$

Tanım: Geniş ağızlı ve küresel gövdelidir. Kaidesi halka biçimli olup yüksektir. Koyu kahverengi (7.5 YR 3/4) mat ve yer yer bozulmuş astar. Koyu kahverengi (7.5. YR 4/6), az mika ve ince kum katkılı, sert dokulu hamur. Ağızda bazı kısımları kırık ve eksiktir.

\section{Doğu Sigillataları A}

6: Tabak

Env. No: 6534

Çiz. No: $1 / 6$

Tanım: Geniş ağızlı, dairesel gövdelidir. Düz kaidelidir. Kırmızı renk (2.5 YR 4/6) parlak ve perdahlı astar. Sarımsı kırmızı renk (5 YR 5/6), mikasız, oldukça sert dokulu hamur. 
7: Tabak

Env. No: 7298

Çiz. No: $1 / 7$

Tanım: Geniş ağızı ıe halka kaidelidir. Kırmızı renk (10 R 4/8) parlak ve perdahlı, yer yer aşınmış astar. Sarımsı kırmızı renk (5 YR 5/8), mikasız, oldukça sert dokulu hamur.

\section{Pergamon - Doğu Sigillataları C}

8: Kase

Env. No: $7299 \quad$ Çiz. No: 1/8

Tanım: Geniş ve yüksek ağızlı, dairesel gövdelidir. Kaidesi halka biçimli olup yüksektir. Kırmızı renk (2.5 YR 4/6) parlak ve perdahlı astar. Kırmızı renk (2.5. YR 5/6), az mika ve ince kum katkılı, sert dokulu hamur.

\section{Doğu Sigillataları B1}

9: Tabak

Env. No: 7291

Çiz. No: $1 / 9$

Tanım: Geniş ağızlı ve yarı küresel gövdeli, düz kaidelidir. Ağız kısmında yer yer kırıklar mevcuttur. Açık kırmızı renk (10 R 6/8) parlak ve perdahlı, yer yer aşınmış astar. Kırmızı renk (2.5 YR 5/6), bol mika katkılı, sert dokulu hamur.

10: Tabak

Env. No: 6533

Çiz. No: $1 / 10$

Tanım: Geniş ağızlı, dairesel gövdelidir. Düz kaidelidir. Kırmızı renk (2.5 YR 4/6) parlak ve perdahlı astar. Açık kırmızı renk (2.5 YR 6/6), bol mika ve ince kum katkılı, sert dokulu hamur.

11: Tabak

Env. No: 6538

Çiz. No: $1 / 11$

Tanım: Geniş ağızlı ve yarı küresel gövdeli, yüksek halka kaidelidir. Ağız kısmında geniş bir yiv bulunmakta. Kırmızı renk (2.5 YR 5/8) parlak ve perdahlı astar. Sarımsı kırmızı renk (5 YR 4/6), bol mika ve ince kum katkılı, sert dokulu hamur. Kırık ve kısmen eksik olup, restorasyon sonrası tümlenmiştir.

12: Tabak

Env. No: 6539

Çiz. No: $1 / 12$

Tanım: Geniş ağızıı ve yarı küresel gövdeli, yüksek halka kaidelidir. Ağız kısmında ince bir yiv bulunmakta. Kırık ve kısmen eksik olup, restorasyon sonrası tümlenmiştir. Koyu kırmızı renk (2.5 YR 3/6) parlak ve perdahlı astar. Kırmızı renk (2.5 YR 5/6), bol mika ve ince kum katkılı, sert dokulu hamur.

13: Kase

Env. No: 6537

Çiz. No: 1/13

Tanım: Geniş ağızı, dairesel gövdelidir. Düz kaidelidir. Açık kırmızı renk (2.5 YR $6 / 8$ ) parlak ve perdahlı astar. Sarımsı kırmızı renk (5 YR 5/8), bol mika ve ince kum katkılı, sert dokulu hamur. 


\section{Doğu Sigillataları B2}

14: Kase

Env. No: 6535

Çiz. No: $2 / 14$

Tanım: Geniş ağızıı ve küresel gövdelidir. Düz kaidelidir. Kırmızı renk (2.5 YR 5/6) parlak ve perdahlı astar. Sarımsı kırmızı renk (5 YR 5/6), az mika katkılı, sert dokulu hamur. Ağızda bazı kısımları kırık olan kap sonradan tümlenmiştir.

15: Kase

Env. No: 6536

Çiz. No: 2/15

Tanım: Geniş ağızlı ve küresel gövdelidir. Düz kaidelidir. Kırmızı renk (2.5 YR 5/6) parlak ve perdahlı astar. Sarımsı kırmızı renk (5 YR 5/6), az mika katkılı, sert dokulu hamur. Ağızda bazı kısımları kırık olan kap sonradan tümlenmiştir.

16: Kase

Env. No:6544

Çiz. No: 2/16

Tanım: Geniş ağızıı ve küresel gövdelidir. Düz kaidelidir. Kırmızı renk (2.5 YR 5/6) parlak ve perdahlı astar. Sarımsı kırmızı renk (5 YR 5/6), az mika katkılı, sert dokulu hamur. Ağızda bazı kısımları kırık olan kap sonradan tümlenmiştir.

17: Kase

Env. No: 6545

Çiz. No: $2 / 17$

Tanım: Geniş ağızlı ve küresel gövdelidir. Düz kaidelidir. Kırmızı renk (2.5 YR 5/6) parlak ve perdahlı astar. Sarımsı kırmızı renk (5 YR 5/6), az mika katkılı, sert dokulu hamur. Ağızda bazı kısımları kırık olan kap sonradan tümlenmiştir.

18: Kase

Env. No: 7289

Çiz. No: $2 / 18$

Tanım: Geniş ağızlı ve yarı küresel gövdeli, düz kaidelidir. Ağız kısmında yer yer kırıklar mevcut olup, restorasyon sonrası tamamlanmıştr. Kırmızı renk (10 R 5/6) parlak ve perdahlı, yer yer aşınmış astar. Kırmızı renk (2.5 YR 5/8), az mika katkılı, sert dokulu hamur.

19: Kase

Env. No: 7290

Çiz. No: 2/19

Tanım: Geniş ağızıı ve yarı küresel gövdeli, düz kaidelidir. Ağız kısmında yer yer kırıklar mevcut olup, restorasyon sonrası tamamlanmıştır. Açık kırmızı renk (10 R $6 / 8$ ) parlak ve perdahlı, yer yer aşınmış astar. Kırmızı renk (2.5 YR 5/6), az mika katkılı, sert dokulu hamur.

20: Kase

Env. No: 7292

Çiz. No: $2 / 20$

Tanım: Geniş ağızlı ve küresel gövdelidir. Düz kaidelidir. Açık kırmızı renk (2.5 YR 6/8) parlak ve perdahlı astar. Açık kırmızı renk (2.5. YR 6/6), az mika katkılı, sert dokulu hamur. 
21: Kase

Env. No: 7293

Çiz. No: 2/21

Tanım: Geniş ağızlı ve küresel gövdelidir. Düz kaidelidir. Açık kırmızı renk (2.5 YR $7 / 8$ ) parlak ve perdahlı astar. Açık kırmızı renk (2.5 YR 6/6), az mika katkılı ve sert dokulu hamur. Eser yer yer kırık olup sonradan tümlenmiştir.

22: Kase

Env. No: 7296

Çiz. No: $2 / 22$

Tanım: Geniş ağızlı ve küresel gövdelidir. Düz kaidelidir. Kırmızımsı sarı renk (5 YR 6/8) parlak ve perdahlı astar. Sarımsı kırmızı renk (5 YR 5/8), az mika katkılı ve sert dokulu hamur.

23: Tabak

Env. No:7294

Çiz. No: $2 / 23$

Tanım: Geniş ağızı ve düz kaidelidir. Ağız dış kısmında derin, kaide iç kısımda ise dairesel ince yivler mevcuttur. Kırmızı renk (2.5 YR 5/6) parlak ve perdahlı, yer yer aşınmış astar. Koyu kırmızı renk (2.5 YR 3/6), az mika katkılı, sert dokulu hamur.

24: Tabak

Env. No: 7295

Çiz. No: $2 / 24$

Tanım: Geniş ağızlı ve düz kaidelidir. Kırmızı renk (10 R 4/8) parlak ve perdahlı, yer yer aşınmış astar. Sarımsı kırmızı renk (5 YR 5/8), az mika katkılı, sert dokulu hamur.

25: Kase

Env. No: 6547

Çiz. No: $2 / 25$

Tanım: Geniş ve yayvan ağızlı, küresel gövdelidir. Kaidesi halka biçimli olup alçaktır. Kabın iç kısmında baskı tekniğinde yapılmış bir başak bezemesi bulunur. Açık kırmızı renk (2.5 YR 6/8) oldukça parlak ve perdahlı astar. Kırmızımsı sarı renk (5 YR 7/8), katkısız sert dokulu hamur.

\section{ince Cidarlı Roma kapları}

26: Maşrapa

Env. No:6546

Çiz. No: $3 / 26$

Tanım: Tek kulplu, küresel gövdelidir. Kısa boyunlu olup, gövdeden ağıza geçiş kısmında derin bir yiv mevcuttur. Geniş ağızlı ve yüksek halka kaidelidir. Sarımsı kırmızı renk (5 YR 4/6) mat ve yer yer aşınmış astar. Gövde üzerinde bazı akıtma ve boya izleri bulunmakta. Kırmızımsı sarı renk (5 YR 5/6), az mika ve ince kum katkılı, orta sert dokulu hamur. 
27: Maşrapa

Env. No:7037

Çiz. No: 3/27

Tanım: Tek kulplu, küresel gövdelidir. Kısa boyunlu olup, gövdeden ağıza geçiş kısmında derin bir yiv mevcuttur. Geniş ağızlı ve düz kaidelidir. Kırmızımsı sarı renk (5 YR 6/8) mat ve yer yer aşınmış, pürüzlü astar. Gövde üzerinde delikler, bazı akıtma ve boya izleri bulunmakta. Kırmızımsı sarı renk (5 YR 6/6), az mika, ince kum ve taşçık katkılı, orta sert dokulu hamur.

28: Maşrapa

Env. No:7038

Çiz. No: $3 / 28$

Tanım: Tek kulplu, küresel gövdelidir. Kısa boyunlu olup, geniş ve dışa doğru açılan bir ağzı vardır. Geniş ağızlı ve düz kaidelidir. Koyu kahverengi (7.5 YR 4/6) mat ve yer yer aşınmış, pürüzlü astar, üzerinde is ve yanıklar bulunmakta. Koyu kahverengi (7.5 YR 4/6), kum ve taşçık katkılı, orta sert dokulu hamur.

29: Maşrapa

Env. No:7039

Çiz. No: $3 / 29$

Tanım: Tek kulplu, ortası şişkin, küresel gövdelidir. Kısa boyunlu olup, gövdeden ağıza geçiş kısmında derin bir yiv mevcuttur. Geniş ağızlı ve düz kaidelidir. Koyu kahverengi (7.5 YR 4/6) mat ve yer yer aşınmış, pürüzlü astar. Koyu kahverengi (7.5 YR 5/8), az mika, ince kum ve taşçı katkılı, sert dokulu hamur.

30: Bardak

Env. No:7040

Çiz. No: $3 / 30$

Tanım: Dibe doğru daralan, yarı silindirik gövdelidir. İçe doğru çekik geniş bir ağzı mevcut olup, düz kaidelidir. Koyu kahverengi (7.5YR 3/2), mat ve yer yer aşınmış astar. Koyu kahverengi (7.5 YR 5/6), az mika ve ince kum katkılı, sert dokulu hamur.

\section{SONUÇ}

Sonuç olarak, Tabae'da başta kase ve tabaklar olmak üzere, ince sofra kaplarından oluşan kırmızı astarlı Roma kaplarının ağılıklı olarak ithal mallardan meydana geldiği söylenebilir. Şimdilik katalogda ele alınan 30 eserden mevcut ince sofra kaplarının kullanıldığı ithal hamurların, Tabae'da ele geçen toplam 226 adet Roma kabı içerisinde \% 12'lik bir orana sahip olduğundan daha önce bahsetmiştik.

Bunların kendi içerisindeki istatistiksel dağıımına baktığımız vakit, Doğu Sigillata B grubuna dahil edilebilecek kase veya tabakların sayısal olarak en büyük grubu oluşturduğu ve toplam 17 eser ile $\% 55^{\prime}$ lik oldukça yüksek bir orana sahip olduğunu söyleyebiliriz. Bu gruba dahil edilebilecek kaplarında \%39'u, toplam sayıları 12 olan Doğu Sigillata B2 grubuna atfedilir. Sayıları sadece 5 olan \% 16'lık küçük bir bölüm ise Doğu Sigillataları B1 grubuna aittir. Hellenistik karakterdeki içe çekik ağızlı kaselerin de sayısal olarak 5 adet ile \%16'lık bir orana sahip oldukları, Doğu Sigillataları A ve Doğu Sigillataları C grubuna dahil edilebilecek kase yada tabakların ise ikişer adetle toplamda \%13'lük bir orana sahip oldukları görülebilir. İnce cidarlı maşrapa ya da kadeh benzeri kapların ise toplam 5 adet ile \%16'lık bir seviyede olduğunu söyleyebiliriz (Res. 8). 


\section{Uluslararası Sosyal Bilimler Dergisi}

\section{kırmızı astarlı ince sofra kaplarının form ve biçim olarak} orantısal dağılımları

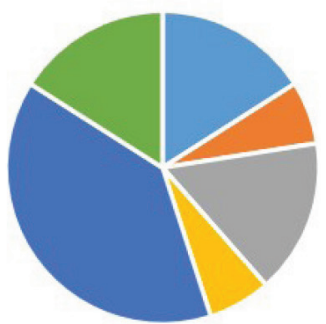

- Hellenistik kaseler: 16

- Doğu Sigillata A: 6,5

- Doğu Sigillata B1: 16

= Doğu Sigillata C: 6,5

- Doğu Sigillata B2: 39

- İnce cidarlı maşrapa ve kadehler: 16

Resim 8. Tabae'daki kırmızı astarlı ince sofra kaplarının form ve biçim olarak orantısal dağılımları.

Tarihlendirilmeleri en iyi olarak yapılabilen bu ithal ve ithal benzeri kırmızı astarlı ince sofra kaplarından, Doğu Sigillata B ve C grubuna dahil edilebilecek malların ağırlıklı olarak M.S. 1. ve 2. yüzyıllara, Hellenistik kaseler ile birlikte Doğu Sigillata A grubuna dahil edilebilecek malların da M.Ö. 3. ve 2. yüzyıllara ait olduklarını söyleyebiliriz. Aynı şekilde ince cidarlı maşrapa ya da kadehlerin de M.Ö. 1. yüzyıl ile M.S. 1. ya da 2. yüzyıl arasındaki bir zamana tarihlendiklerini görmekteyiz.

Tabae'nin kırmızı astarlı Roma seramiklerini değerlendirdiğimiz bu kısa çalışma sonrasında elde edilen verilerden çıkarılacak bir diğer sonuç da, Tabae'nin Hellenistik dönemin sonlarından itibaren yakın çevresi ile yoğun bir ticari ilişkisinin bulunduğudur. Özellikle de Doğu Sigillataları olarak adlandırılan Batı Anadolu orijinli kırmızı astarlı seramiklerin varlığı, burada Roma'nın imparatorluk dönemi ile birlikte gerek ticari gerekse siyasi ilişkilerde bir artış yaşandığını ve yaklaşık olarak M.S. 2. yüzyıla kadar da bu ilişkilerin yoğun biçimde devam ettiğini göstermektedir. Bu dönem, aynı zamanda Tabae'nin kendi sikkelerini darp ettiği, gerek yazılı ve gerek se arkeolojik kentin gelişim içerisinde olduğunun kanıtlandığı bir dönemdir. Bu süreçte Tabae yakın ve çevre komşuları başta olmak üzere, başta Ephesos, Pergamon, Trailleis ve Smyrna olmak üzere, Batı Anadolu'daki önemli merkezler ile yoğun bir ticari ilişki içerisine girmiş ve bölgedeki önemli şehirlerden biri olmuştur. 


\section{KAYNAKÇA}

Beyazıt M., "Kale-i Tavas (Tabae) Kazıları”, Geçmişten Günümüze Denizli, Denizli'nin Derin Geçmişi, Kazı ve Araştirmalar II, 2016. s: 64-77.

Erol, D., Tralleis Kenti Kazılarında Ele Geçen isim Baskılı Terra Sigillatalar, Adnan Menderes Üniversitesi Sosyal Bilimler Enstitüsü (Yayımlanmamış Yüksek Lisans Tezi), Aydın. 2004.

Erol, D., "Symrna Devlet Agora Buluntusu Terra Sigillatalari", Çanak, Late Antique and Medieval Pottery and Tiles in Mediterranean Archaeological Contexts, Proceedings of the First International Symposium Late Antique and Medieval Pottery and Tiles in Archaeological Contexts, (Çanakkale 1-3 June 2005), (eds. Beate Böhlendorf-Arslan - Ali Osman Uysal - Johanna Witte-Orr), İstanbul. 2007, s: 73-95.

Ersoy, B., "Kale-i Tavas (Tabae) Kazıları”, Ege Üniversitesi Arkeoloji Kazıları (ed: A. Çilingiroğlu vd.), İzmir. 2012, s: 415-439.

Ersoy, B., "Kale-i Tavas (Tabae) 2007 Yılı Kazısı", Kazı Sonucları Toplantısı 30/3, Ankara. 2009, s: 43-45.

Ersoy, B., "Kale-i Tavas (Tabae) 2008 Yılı Kazı Çalışmaları", Kazı Sonucları Toplantısı 31/3, Ankara. 2010, s: 302303.

Gassner, V., Das Südtor der Tetragonos Agora. Keramik und Kleinfunde, Forschungen in Ephesos 13, Wien. 1997.

Goldman, H., Excavations at Gözlükule. Tarsus Volume I, Princeton. 1950.

Gök, S. - Uçar H., "Kale-i Tavas (Tabae) Kazısı Seramik Buluntuları (2007-2011) " Kaledavaz Sempozyum Bildirileri (2-3 Nisan 2012), (ed: T. Tok - Ö.K. Aydemir), Denizli. 2013, s: 402-412.

Gürtekin-Demir, R. G. - Polat, Y., "Between Lydia and Caria: Iroın Age pottery From Kale-i Tavas, Ancient Tabae", Karamos, Ceramics: A Cultural Approach. Proceedings of the First International Conference at Ege University (9-13 May 2011), (ed: R.G. Gültekin-Demir et al), Ankara. 2015, s: 115-136.

Hayes, J. W., Late Roman Pottery, Rome, 1972.

Hayes, J. W., "Roman Pottery from the South Stoa at Corinth", Hesperia 42, 1973, s: 416-486.

Hayes, J. W., Roman Pottery in the Royal Ontario Museum, Toronto, 1976.

Hayes, J. W., "Sigillate Orientali", Enciclopedia dell'Arte Classica e Orientale. Atlante delle Forme Ceramiche II: Ceramica Fine Romana nel Bacino Mediterraneo (Tardo Ellenismo e Primo Imperio), Roma. 1985, s: $1-96$.

Hayes, J. W., Paphos III. The Hellenistic and Roman Pottery, Nicosia. 1991.

Hayes, J. W., Handbook of Mediterranean Roman Pottery, Norman. 1997.

Hayes, J. W., Roman Pottery. Fine-ware Imports. The Athenian agora: results of excavations conducted by the American School of Classical Studies at Athens 32, Princeton. 2008.

Jones, F. F., The Pottery, Excavations at Gözlü Kule, Tarsus, Vol. I. (ed:H. Goldman), London. 1950.

Meriç, R., Spathellenistisch- Römische Keramik und Kleifunde aus Einem Schachtbrunnen amStaatsmarkt in Ephesos, FiE IX/3, Wien. 2003.

Meyer-Schlichtmann, C., Die Pergamenische Sigillata aus Der Statgrabung von Bergama, PF6, Berlin-New York. 1988.

Ramsay, W.M., The Historical Geography of Asia Minor, London. 1890.

Robinson, H. S., Pottery of the Roman Period, Athenian Agora V, Princeton. 1959.

Rotroff, S. I., Hellenistic Pottery Athenian and Imported Wheelmade Table Ware and Related Material, Princeton. 1997.

Rotroff, S. I., Hellenistic Pottery The Plain Wares, The Athenian Agora XXXIII, Princeton. 2006.

Strabon, Geographika. Antik Anadolu Coğrafyası (çev. A. Pekman), İstanbul. 2000.

Talbert, R. J. A. (ed.), Barrington Atlas of the Greek and Roman World, Princeton. 2000.

Ünal, C., "Coin Findings and Two German Tokens from Excavation of Tabae/Kale, Denizli", Sanat Tarihi Dergisi XVIII/2, 2009, s: 137-155.

Williams, C., Anemurium. The Roman and Early Byzantine Pottery, Wetteren. 1989.

Zoroglu, L., "Dogu Sigillataların İmalat Yerleri ve Dağılım Sorunu", Varia Anatolica XV; Les Ceramiques En Anatolie Aux Epoques Hellenistique et Romane, (ed. C. Abadie-Reynal), İstanbul. 2003, s. 121-123. 

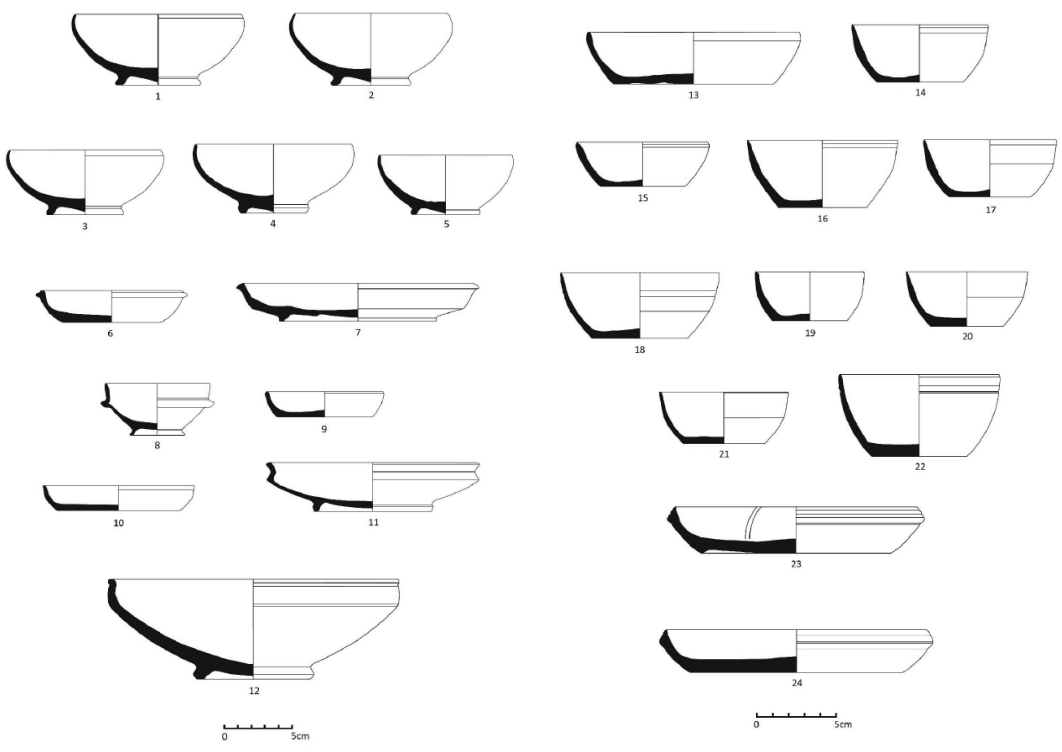

Çizim 1. 1-12 katalog numaralı eserler.

Çizim 2. 13-24 katalog numaralı eserler.
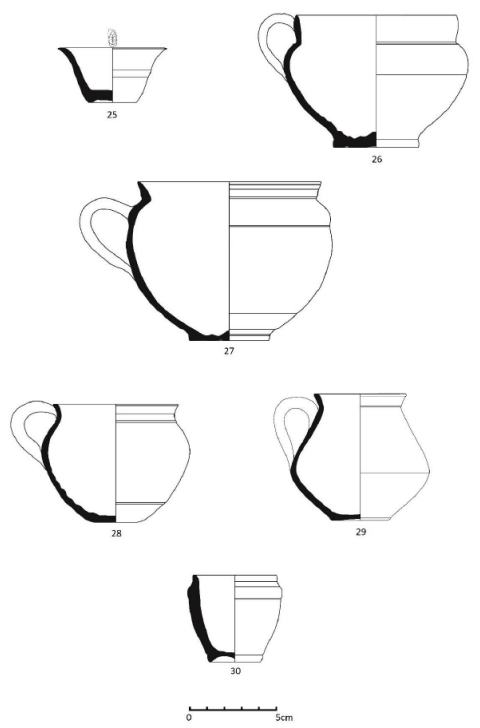

Çizim 3. 25-30 katalog numaralı eserler. 